\title{
EXPERIÊNCIAS MONTESSORIANAS NO PROJETO DE EXTENSÃO LUDOTECA EM MOVIMENTO DA UNIVERSIDADE ESTADUAL DE LONDRINA
}

\author{
Marta Regina Furlan de Oliveira \\ Anilde Tombolato Tavares da Silva \\ Candida Alayde de Carvalho Bittencourt \\ Universidade Estadual de Londrina (UEL)
}

\section{RESUMO}

Este artigo objetiva compartilhar as experiências do Projeto de Extensão - Ludoteca em Movimento - da Universidade Estadual de Londrina, Paraná - Brasil que atende crianças entre 4 a 10 anos em um espaço alocado no próprio Campus Universitário. A nossa inquietação parte deste contexto contemporâneo que negligencia a criança como um ser ativo, criativo e há um empobrecimento das relações ente adultos e crianças negando-lhe o direito de ser criança. Neste sentido, a obra de Maria Montessori se constitui indubitavelmente numa bela e fecunda contribuição para as atividades lúdicas e expressivas das crianças que participam do projeto. $\mathrm{O}$ ambiente foi organizado com a influência, entre outros, do método montessoriano, sendo organizado com espaços adequados, silencioso e em contato com a natureza. Assim, as crianças desenvolvem experiências sensoriais diversas: brincadeiras individuais e coletivas, exercícios físicos e intelectivos, experiências sensoriais com música, arte e criações diversas, de maneira que venham a favorecer o desenvolvimento integral e totalizante da criança enquanto ser humano. Acreditamos, então, que a criança deve ser autora de sua própria educação e de sua própria história social. Inferimos que uma educação lúdica pode extrapolar as dimensões espaciais e físicas de confinamento: “(...) não é a de quatro paredes, entre as quais as crianças são confinadas, mas a de uma casa onde possam viver em liberdade para aprender e crescer (...), onde elas possam encontrar atividades condizentes com seu desenvolvimento físico e mental" (MONTESSORI, 1961, p.17).

Palavras-chave: atividades lúdicas; Maria Montessori; educação lúdica; experiências sensoriais

\section{MONTESSORIAN EXPERIENCES IN THE EXTENSION PROJECT LUDOTECA IN MOVEMENT FROM STATE UNIVERSITY OF LONDRINA}

\begin{abstract}
The objective of this article is to share the experience from extension project - Ludoteca in movement- from state University of Londrina, Paraná - Brazil that support children between 4 and 10 years old in a space allocated in the university campus. Our uneasiness comes from the comtemporary context that neglect children as an active being, creative and there is an imporverishment in the relation between adults and children denying the right of being a child. In this way, the work of Maria Montessori is constituted, with no doubt, as a beautiful and big expressive contribution to the playful activities from the children that participate on the project. The environment was organized with the influence, between others, of Montessorian method, being organized with adequated, quiet and contact with nature space. So, as children develop diverse sensitive experience: individual and collective games, phisical and intelectual exercises, sensitive experience with music, art and many creations, to support the integral development of a child as a human being. We believe, then, that a child must be the author of his/her own education and social history. We infer that a playful education can extrapolate the space and phisical dimension of confining:"(...) it is not the four walls, which the children are confined, but a house where they can live with freedom to learn and grow up (...), where they can find activities connected with their phisical and mental development" (MONTESSORI, 1961, p.17). Key words: Playfulness; Maria Montessori; Education; Sensitive Experience
\end{abstract}




\section{Introdução}

Este artigo tem o objetivo de compartilhar as experiências do Projeto de Extensão Ludoteca em Movimento - da Universidade Estadual de Londrina, Paraná - Brasil vinculado ao grupo de Formação de Professores de Educação Infantil e, representado por docentes do Departamento de Educação e Artes Visuais desta instituição. Atende crianças entre 4 a 10 anos em um espaço alocado no próprio Campus Universitário, com áreas distribuídas para que haja um trabalho rico e de possibilidades para com as crianças.

Diante da inquietação de um contexto contemporâneo que negligencia a criança como um ser ativo, criativo; há o empobrecimento das relações entre adultos e crianças negando à criança o seu direito de ser criança. Diante disto, a obra de Maria Montessori se constitui indubitavelmente numa bela e fecunda contribuição para as atividades lúdicas e expressivas das crianças que participam do projeto; já que o olhar montessoriano, ressignifica a criança enquanto ser ativo, expressivo, autônomo e livre para construir sua aprendizagem e suas leituras de mundo.

Sabe-se, portanto, que o universo infantil atualmente, precisa de um lugar próprio, diferenciado do mundo adulto, sendo direito e necessidade das crianças. Além disso, os conceitos destinados a infância e ao ser criança enquanto reprodução do mundo adulto devem ser superados, dando-lhes o direito de se expressar livremente conforme suas conquistas psíquicas e sensoriais. Ao professor cabe o papel de observar muito mais do que ensinar, já que segundo a autora, "sua função consiste em dirigir as atividades psíquicas das crianças bem como seu desenvolvimento fisiológico" (MONTESSORI, 1969 p.156).

Vários assuntos são discutidos por Montessori, sendo que um deles é de extrema relevância quando aproximamos o método às experiências no espaço Ludoteca da Universidade. A autora coloca a criança (e não mais o professor) no centro do processo educativo, já que esta se desenvolve espontaneamente através de experiências vividas no ambiente. O professor deixa de ser fonte de conhecimento e sua tarefa fundamental passa a ser o de mediar a criança a reconhecer e desenvolver - por si mesma - suas potencialidades. Neste sentido, a educação torna-se uma conquista da criança, desde que lhe sejam dadas as devidas condições.

As condições enfatizadas por Montessori, podem ser exemplificadas pelo ambiente preparado e organizado; o educador preparado; a incessante construção da autonomia infantil; a busca e a valorização da espontaneidade infantil a partir do interesse próprio da criança; as brincadeiras e experiências sensoriais estimulam o desenvolvimento psíquico infantil, entre outros temas.

\footnotetext{
Podemos dizer que adquirimos os conhecimentos com a nossa inteligência, enquanto que a criança os absorve com a sua vida psíquica. Simplesmente, continuando a viver, a criança aprende a falar a língua da sua raça. É uma espécie de química mental que se opera nela. Somos recipientes; as impressões vertem-se em nós e nós recordamo-las e retemo-las na mente, mas ficamos diferentes das nossas impressões, como a água fica diferente no copo. A criança, pelo contrário, sofre uma transformação: as impressões não só penetram na sua mente mas formam-na. Encarnam nela. A criança cria a própria 'carne mental', usando as coisas que estão no seu ambiente. Chamamos ao seu tipo de mente 'Mente absorvente'. É difícil para nós conceber as faculdades da mente infantil, mas sem dúvida se trata de uma forma de mente privilegiada" (MONTESSORI, 1985 p.27).
}

O ambiente da Ludoteca foi organizado com a influência, entre outros, do método montessoriano, sendo organizado com espaços adequados, silenciosos e em contato com a natureza. Os móveis são acessíveis ao tamanho da criança para que esta tenha liberdade para se comunicar e movimentar-se livremente (LAMORÉA,1996). Neste espaço, as crianças 
desenvolvem experiências sensoriais diversas: brincadeiras individuais e coletivas, exercícios físicos e intelectivos, experiências sensoriais com música, arte e criações diversas, de maneira que venha a favorecer o desenvolvimento integral e totalizante da criança enquanto ser humano. O objetivo é educar a criança para a liberdade, estimulando-a a atividade livre e, possibilitando-a o desenvolvimento da autoeducação e autonomia.

A metodologia valoriza a aprendizagem ativa, envolvendo as crianças em todas as situações educativas do espaço lúdico e, para além dele. Os mediadores possibilitam o desenvolvimento da capacidade da criança crescer de maneira autônoma, favorecendo assim, a libertação interior da mesma em relação ao outro pela socialização lúdica. Acreditamos, então, que criança deve ser autora de sua própria educação e de sua própria história social. Inferimos que uma educação lúdica pode extrapolar as dimensões espaciais e físicas de confinamento: “(...) não é a de quatro paredes, entre as quais as crianças são confinadas, mas a de uma casa onde possam viver em liberdade para aprender e crescer (...), onde elas possam encontrar atividades condizentes com seu desenvolvimento físico e mental" (MONTESSORI, 1961, p.17).

\section{Ludoteca em Movimento: experiências montessorianas}

Ludoteca em Movimento é um Projeto desenvolvido numa parceria entre os Departamentos de Educação e Departamento de Artes Visuais da Universidade Estadual de Londrina, com objetivo de trabalhar junto com os acadêmicos vinculados a diferentes áreas do conhecimento, escolas filantrópicas e instituições educativas não formais que apresentam interesse pelo brincar, brincadeiras lúdicas e criatividade no contexto educativo com crianças de 4 a 10 anos. Caracteriza-se por frentes básicas de atuação no espaço lúdico situado no campus da Universidade Estadual de Londrina e atividades nas Instituições escolares formais e não formais de Londrina/Pr. O trabalho desenvolvido com as crianças tem apresentado resultados significativos especialmente destacando a importância do brincar como aspecto importante no desenvolvimento da criança na sua totalidade.

Considerando a importância significativa do brincar e das diversas atividades lúdicas que as crianças precisam, bem como, a relevância dos educadores voltarem seu olhar para o brincar é que surgiu a necessidade de criar o projeto "Ludoteca em Movimento", levando a ludicidade até as crianças e seus professores promovendo atividades que visam a interação com o lúdico e a cultura do brincar, utilizando situações prazerosas, que possibilitem o desenvolvimento de habilidades, às crianças que, por diferentes razões, não tinham acesso a um contexto lúdico e se distanciam de sua própria cultura.

O projeto foi criado a partir da experiência que o Programa de Extensão Ludoteca/UEL vinha desenvolvendo desde 1988, onde propunha atividades lúdicas com crianças, filhos de funcionários da Instituição no espaço lúdico dentro do campus universitário. Visando a ampliação do atendimento à comunidade nasce o desejo de compartilhar saberes e fazeres que permeiam o desenvolvimento infantil para levar a ludicidade aos diferentes espaços, tais como: escolas, hospitais e centros comunitários. Com atendimento semanal, promove atividades que visam a interação com o lúdico, utilizando situações prazerosas, que possibilite o desenvolvimento de habilidades das crianças de 04 a 10 anos.

Como o próprio nome ressalta estar em movimento é lançar mão de uma proposta integradora com a comunidade, propiciando Ensino, Pesquisa e Extensão. Um movimento de ir além da Universidade e propiciar possibilidades de desenvolver um olhar que considere a criança como sujeita de direitos, alguém com voz e vez, garantindo-lhe o direito à infância, assim como preconiza Montessori em sua obra A criança. E neste sentido, o objetivo principal do projeto é o de oferecer essas atividades não somente para as crianças, mas também num trabalho de integração entre formação de professores, outros profissionais envolvidos com as instituições, e 
estagiários pertencentes ao projeto, buscando uma ramificação e mobilidade, levando o brincar e diversas atividades lúdicas aos diferentes espaços.

As atividades são realizadas em duas frentes: no espaço físico do Programa Ludoteca/UEL localizado no campus universitário e nas instituições educativas, levando sempre como filosofia básica dois aspectos fundamentais, o primeiro de possibilitar às crianças o acesso e a "livre escolha" do brinquedo/brincadeira, em situação de mediação e o segundo aspecto o de priorizar o enfoque interdisciplinar, possibilitando reflexões e discussões de temas relacionados à criança e ao lúdico. Pela ação interdisciplinar há discussões em grupo entre discentes de diferentes áreas de atuação e docentes de áreas específicas.

Por meio de atividades lúdicas, oficinas e brincadeiras ao ar livre e que envolvam a criatividade e imaginação, tentou resgatar a importância do brincar e das brincadeiras contrapondo-se ao brincar encarcerado e tecnológico da sociedade moderna, desenvolvendo atividades que visam a interação com o lúdico, utilizando situações prazerosas, possibilitando o desenvolvimento de habilidades das crianças das instituições educativas.

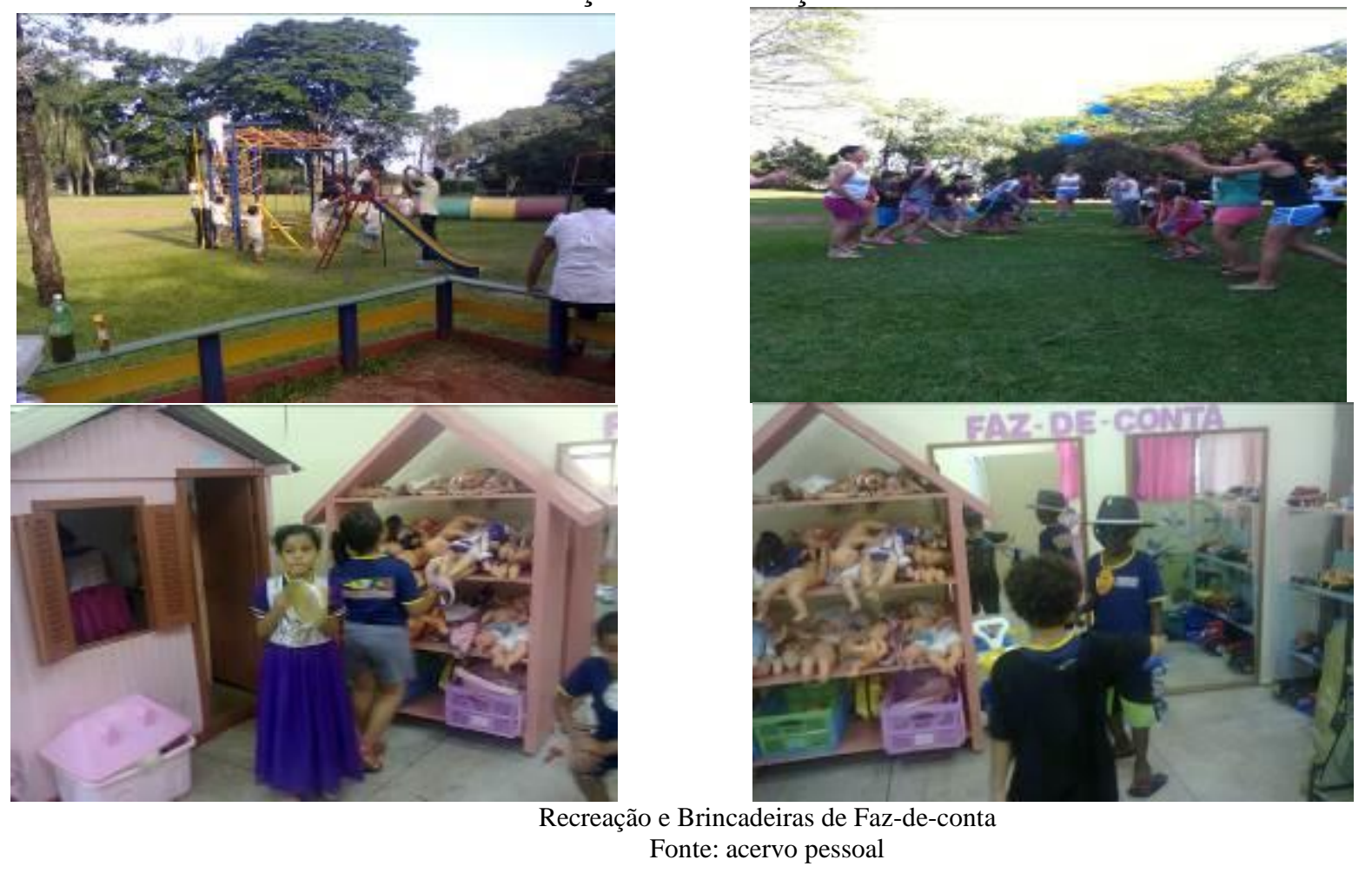

A proposta possibilita à criança vivenciar situações lúdicas em ambientes internos e externos. O espaço interno é composto de canto da leitura, dos fantoches, casinha de boneca, canto do vídeo, dos jogos, da arte, dos castelinhos de bola, da fantasia, das bonecas, carrinhos. No espaço externo as árvores, ao redor, são o único limite, pois não há grades, nem cercas para cercear o espaço de brincar das crianças. Podem viver suas experiências no campo de futebol, na amarelinha, na pista para perna-de-pau, no bambolê, no pular cordas, no jogo de bets, no escorregador, na escalada, no trenó de grama, entre outras possibilidades que a imaginação permite, pois conforme nos assegura Montessori (1972 p.82):

O primeiro passo da educação é prover a criança de um meio que lhe permita desenvolver as funções que lhes foram designadas pela natureza. Isso não significa que devemos contentá-la e deixá-la fazer tudo o que lhe agrada, mas nos dispor a colaborar com a ordem da natureza, com uma de suas leis, que quer que esse desenvolvimento se efetue por experiências próprias da criança. 
Nas instituições educativas a mesma experiência é desenvolvida com os brinquedos, pernas de pau, bambolês, trenó de grama, fantoches, jogos e outros recursos de artes visuais, como oficinas de artes com sucatas, argila, releituras de obras de arte, entre outros. Buscamos enfatizar a intencionalidade das ações partindo de leituras e planejamentos organizados pelos envolvidos no projeto. E, especialmente poder ofertar oficinas aos estudantes e professores que atuam diretamente com as crianças no sentido de contribuir na formação teórico prática e ampliar seus conhecimentos em relação à importância do brincar para, conforme nos indica Montessori, auxiliar no desenvolvimento natural das crianças.

Nos espaços livres do campus universitário, tentamos resgatar a ludicidade no brincar e estimular a criatividade e imaginação por meio da escolha livre onde as crianças se deparam com novas formas de brincar, de criar, de interagir, de se desenvolver e de se divertir, pois brincando a criança aprende de uma forma divertida, "todos podem inventar e criar se forem estimulados a fazê-lo" (CUNHA, 2010, p. 92).

Essas atividades propostas não seriam produtivas se nós não entendêssemos a criança em sua plenitude, pois o próprio conceito de ser criança foi mudando histórica e socialmente. Incompreendida pelos padrões existentes que consideravam somente o adulto, a criança foi vista, por muito tempo como um recipiente vazio que os adultos precisavam preencher segundo seus próprios padrões. Desconhecia-se que as crianças se desenvolvessem no ambiente social e que necessitassem de liberdade e segurança para construírem sua identidade e autonomia. Diante disso, o desafio é o de construir a identidade infantil, conhecendo seus próprios gostos e preferências e, com isso, estimular suas habilidades e limites, sempre levando em conta a cultura, a sociedade, o ambiente e as pessoas com quem se convive. Nesse sentido, a autonomia e a capacidade de conduzir e tomar decisões por si próprio levando em conta as regras, os valores e a perspectiva pessoal, bem como a perspectiva do outro, é a proposta de educação e ludicidade para a infância (MONTESSORI, 1972).

A contemporaneidade privou a criança do ambiente social, de liberdade confinandoa, cada vez mais, a ambientes fechados e regrados. Entretanto, conforme contribuições montessorianas, na ludoteca a liberdade é algo que a criança deve conquistar e que envolve livrála de obstáculos que impedem o desenvolvimento normal de sua vida. Para Montessori, as crianças são "potencialmente boas" e devem ser respeitadas para que possam respeitar os outros (MONTESSORI, 1952 p. 16).

\section{Contribuições de Maria Montessori: do método à organização do espaço e interações}

Ao buscar a compreensão acerca das contribuições de Maria Montessori, inicialmente se faz necessário compreender o seu legado maior. Disso, pode-se afirmar que Maria Montessori resumiu sua vida em uma frase, sucintamente relembrada por seu neto, Mário Montessori Jr.: "Eu descobri a criança". É mundialmente conhecida por ter criado o método Montessori (chamado por ela de Pedagogia Científica) e ter revolucionado a forma como a criança é compreendida e respeitada. Em quase todos os países do mundo há escolas montessorianas e diversas iniciativas educacionais revolucionárias tiveram suas bases nas descobertas de Montessori.

Suas contribuições foram e continuam sendo efetivas no campo da educação para a infância, pelo seu olhar à criança e pelos encaminhamentos didáticos e pedagógicos voltados ao trabalho com a educação infantil. Maria Montessori (1870-1952) afirma a existência de uma vida psíquica na criança, qual "embrião espiritual" em desenvolvimento, e defende que o mais urgente dever da educação é "libertar" o indivíduo oculto, ou seja, desvelar a criança desconhecida, "revelar" o seu segredo, criando condições para o desenvolvimento da personalidade infantil. 
Para Montessori a busca pela autonomia e pela construção da própria personalidade está presente na criança desde o seu nascimento, em todos os seus estágios evolutivos. $\mathrm{O}$ alcance desta independência física e mental se dá através do esforço individual da criança à medida que lhe são oferecidas as devidas condições (MONTESSORI, 1972).

Conforme os pressupostos montessorianos, a autonomia infantil para nascer e desenvolver na criança, depende, em grande maioria, da ação do professor e do mediador. Este deve ser responsável pela disponibilização dos materiais apropriados a cada criança, permitindolhe desafios diversos e constantes, em que possibilite o desenvolvimento da autoconfiança infantil e a posteriori a estrutura psíquica autônoma. As questões à luz dos conceitos montessorianos envolve-nos a pensar acerca da organização do ambiente físico e interativo, às experiências e às descobertas sensoriais em que em um processo de experimentos a criança vai desenvolvendo atividades livres e lúdicas, a fim de descobrir suas capacidades e sua própria autonomia infantil.

Essa situação é bem vivenciada no espaço da ludoteca em que as crianças tem a liberdade de construir suas formas de brincar e interagir. Os espaços lúdicos e diversificados como: canto da leitura, espaço para desenhos e criações artísticas, espaço da imaginação com a exploração de fantasias, espaço para o desenvolvimento lógico matemático e experiências sensoriais, espaços externos ao ar livre, acabam contribuindo para que a criança vá se percebendo e percebendo suas potencialidades frente aos desafios e as descobertas.

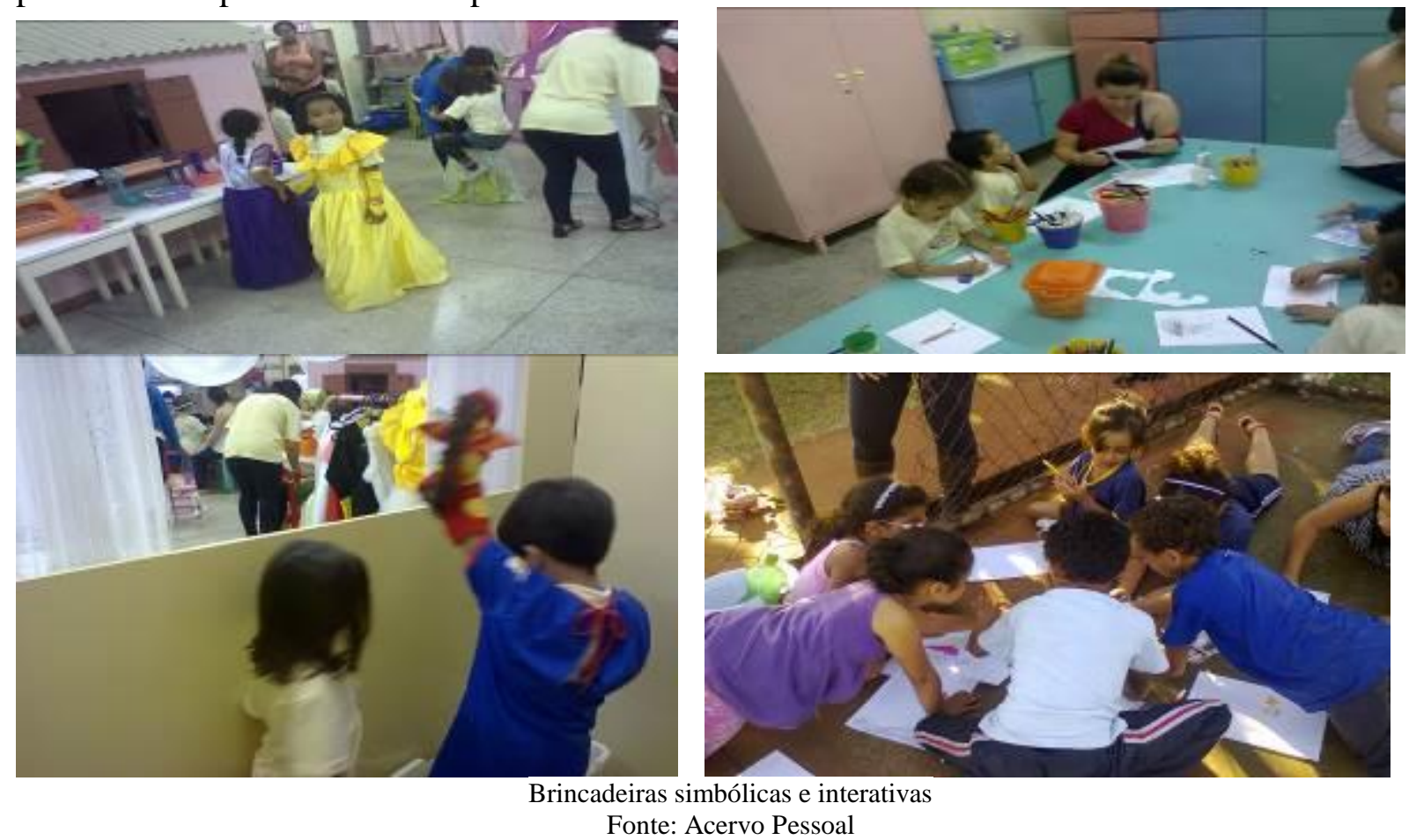

Segundo a autora, a criança possui um poder de sensibilidade tão intenso que as coisas que a circundam despertam nela um interesse e um entusiasmo que parecem penetrar na sua própria vida. A criança assimila todas estas impressões, não com a mente, mas com a própria vida. Para Montessori (1949) a criança precisa de memória para recordar-se das coisas, entretanto, a criança não possui memória, ela deve construí-la. A criança absorve o conhecimento com sua vida psíquica diferentemente da do adulto que adquire conhecimentos através da inteligência. Nos adultos as informações são depositadas sobre suas cabeças e assim recordam e as registram em sua mente. Já na criança as impressões penetram e formam na sua mente.

Nessa perspectiva, a liberdade da criança é associada à sua atividade, correspondente a mediação do adulto, enquanto a criança se auto educa. Além disso, é trabalho do professor 
tornar-se aparentemente dispensável, fazendo com que a criança encontre referências para a realização das atividades dentro dela mesma e não necessariamente na figura do professor. Ao assinalar à educação a finalidade de desenvolver as potencialidades da criança, Montessori tem o propósito de formar uma "criança nova", isto é, o homem de amanhã que habitaria num "mundo novo", uma sociedade de paz: "Um mundo novo para um homem novo, é a nossa necessidade mais urgente" (MONTESSORI, 1965 p.30).

Montessori afirma que a criança possui potencialidades que a torna capaz de construir e desenvolver a autonomia com a mediação indireta do adulto em ambientes favoráveis. Por isso, para a autora o ambiente tem um papel importante, principalmente logo depois do nascimento da criança. $\mathrm{O}$ ambiente que circunda o recém-nascido é importante para que a criança não desenvolva hábitos de regressão, se sentindo rejeitada quando na verdade deveria se sentir atraída pelo ambiente que entrou socialmente.

Por ter uma formação voltada a área da saúde - medicina, Maria Montessori possibilita em seus conceitos e ações inserir conhecimentos da biologia ao serviço da educação das crianças, em que o desenvolvimento infantil aconteça pelo processo de expansão psíquica livre e cerceada de interesses e manifestações que são próprias das crianças. Seu objetivo maior, é possibilitar as crianças condições de viver experiências de liberdade e ação, e ao professor o papel de mediador e orientador da criança para os perigos e para as possíveis descobertas. Todo esse processo, para a autora, só é possível quando se compreende e valoriza o desenvolvimento das potencialidades infantis (MONTESSORI, 1972).

Para isso, quando pensa-se no método, pensa-se em um ambiente que favoreça a expressão do potencial da criança, de forma que o educador crie este ambiente rico de potencialidades e estímulos. Entretanto, Montessori sempre teve a preocupação de deixar clara a ideia de que é a criança que se auto educa. Que ela escolha livremente as suas ocupações e os seus movimentos, buscando na multiplicidade das situações ambientais aquelas que são favoráveis ao seu desenvolvimento e à organização da sua personalidade. O princípio da autoeducação da criança assenta, em primeiro lugar, numa concepção que, inspirando-se em Rousseau, faz coincidir os termos natureza e liberdade.

Contudo, para Montessori esta natureza vem a ser um impulso inato, interior, "uma energia que tende a retirar do ambiente os elementos úteis ao seu desenvolvimento". É esta liberdade da criança que permite as manifestações naturais da mesma e a sua observação pelo educador: $\mathrm{O}$ método da observação é estabelecido sobre uma base fundamental: a liberdade infantil nas suas manifestações espontâneas. Esta liberdade deve, pois, entender-se no sentido de "não dirigida pelos adultos", porquanto a ação é "indireta", isto é, através da construção de um ambiente que permite que a criança possa ser ativa. É, com efeito, a liberdade que está na base da atividade: $O$ método pedagógico da observação tem por base a liberdade da criança; ora liberdade é atividade (CALÓ, MONTESSORI In: CHATEAU, 1956 p.343).

\section{Algumas experiências montessorianas no Projeto Ludoteca em Movimento}

Ao aproximar as contribuições de Maria Montessori ao Projeto Ludoteca em Movimento, abre-nos possibilidades criativas e ricas de aprendizagem juntamente às crianças. Por seu olhar respeitoso e dedicado a criança enquanto sujeito ativo e direito, Montessori nos reforça o desafio do projeto, que acredita que a criança pode desenvolver suas capacidades psíquicas pelo movimento, pela criação e pelas descobertas.

Ainda, quando a autora concede a criança a possibilidade de agir com liberdade e autonomia, neste momento evidenciamos um dos objetivos mais importantes do projeto, já que no contexto atual, a criança tem perdido sua voz e sua ação, no mundo comandado pelos olhares e desejos adultos. Nesse propósito, permitir no espaço da ludoteca, que a criança se descubra enquanto ser potencialmente apto para aprender e se desenvolver, torna-se algo de grande valia 
no campo educacional e de desenvolvimento infantil. Através da experiência do ambiente, sob forma de brincadeira, a criança examina as coisas e as impressões que recebeu na sua mente inconsciente.
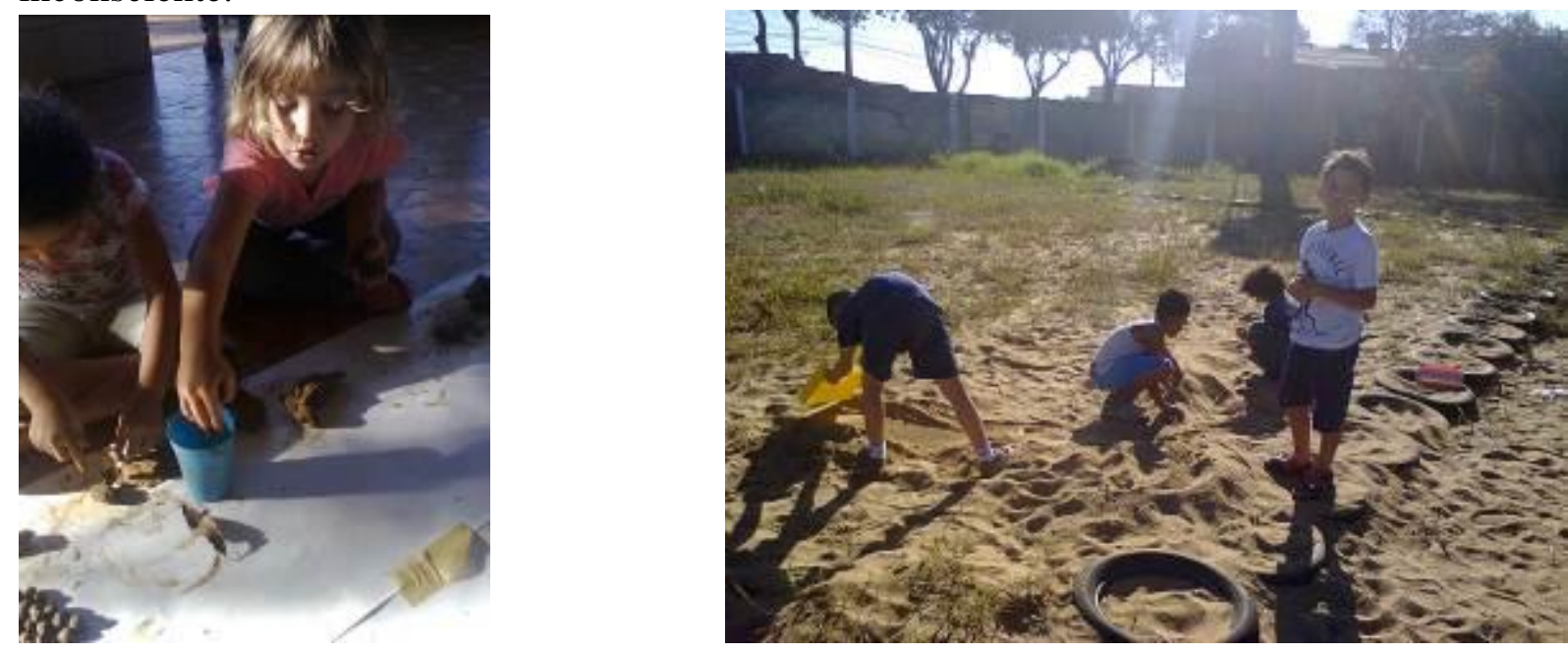

Brincadeiras Manuais e de Modelagem

Fonte: Acervo Pessoal

Montessori acredita que toda criança nasce com sensibilidade e potencialidade precisando ser estimulada adequadamente através do ambiente exterior, para que possa favorecer atividades espontâneas, concentradas, autocorretivas, contribuindo assim para a liberdade, independência e desenvolvimento intelectual das crianças. Ela diz que essa predisposição de construção são os chamados "períodos sensíveis":

Trata-se de sensibilidades especiais que existem nos seres em via de evolução, ou seja, nos estados infantis, as quais são passageiras e limitam-se à aquisição de uma determinada característica. Uma vez desenvolvida essa característica, a sensibilidades cessa e, assim, cada característica se estabelece com o auxílio de um impulso. (MONTESSORI, 1965, p.52).

O "período sensível" da primeira infância oferece a ocasião única de incentivar um desenvolvimento real. Montessori considerava a educação social como um elemento importante dessa primeira fase, visto que a autodeterminação deve receber sua orientação de outrem para que o indivíduo possa atingir a perfeição enquanto ser social. No último capítulo de seu livro $A$ descoberta da criança, ela descreveu esse processo:

Nenhum coração sofre com o bem de outrem, mas o triunfo de um, fonte de encantamento e de alegria para os outros, cria frequentemente imitadores. Todos têm um ar feliz e satisfeito de fazer "o que podem", sem que o que os outros fazem suscite uma vontade ou uma terrível emulação. O pequeno de três anos trabalha pacificamente ao lado de um menino de seis; o pequeno está tranquilo e não inveja a estatura do mais velho. Todos crescem na paz. (Montessori, 1969, p. 33)

Na Ludoteca é dada a extrema importância ao ambiente em que a criança está inserida, justamente para aproveitar o máximo este período sensível da criança que vai dos 4 aos 10 anos de idade. Nesta fase da infância a criança possui muita sensibilidade, destacando-se a ordem do ambiente, por exemplo. Ela gosta e necessita de ordem ao seu redor. Para ela a ordem representa um estímulo, significando para a criança orientação, dominação e segurança no ambiente. Possibilita à criança a capacidade de assumir o ambiente externo, através dos sentidos. Dentro de 
um ambiente, por exemplo, podemos verificar muitas vezes que objetos chamativos apenas distraem a atenção das crianças num certo momento. Irá depender do interesse dela em relação ao objeto. Objetos menores e discretos poderão despertá-las para pequenos detalhes interessantes e importantes para seu desenvolvimento.
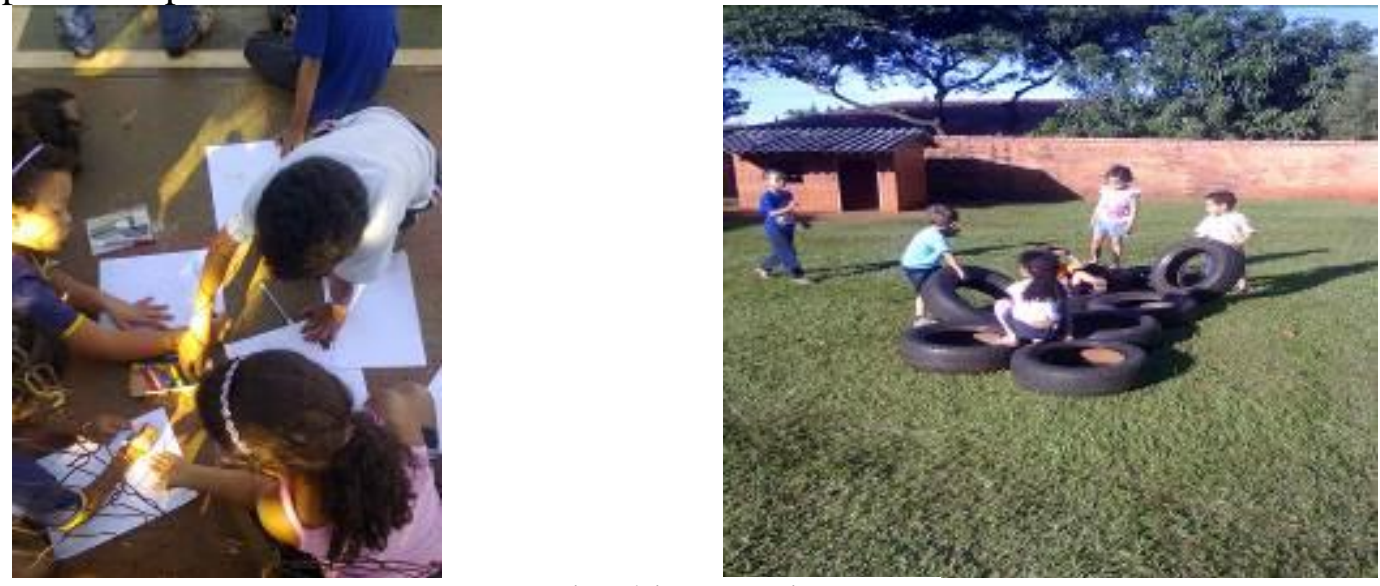

Brincadeiras manuais e motoras

Fonte: Acervo Pessoal

Neste caso a ludoteca tem a preocupação de que esse ambiente seja bem estimulado com cores, formas, texturas, tamanhos e que tenha situações desafiadoras a fim de que as crianças possam aproveitar esse momento para seu desenvolvimento psíquico. O material didático tem igualmente a função de ajudar a criança a crescer em um ambiente harmonioso, a fim de que adquira um senso elevado de responsabilidade. O material, que constitui um dos elementos do "ambiente preparado" da casa das crianças, é metodicamente concebido e padronizado, de maneira que a criança que tenha escolhido livremente se ocupar de um dos objetos propostos se encontre localizada em uma situação previamente determinada e fosse conduzida, sem saber, a encarar o seu desígnio intelectual. O melhor exemplo que podemos dar disso é o exercício de encaixar: cilindros de diferentes tamanhos e cortes devem ser introduzidos nas cavidades adaptadas; uma única solução é possível e, assim, a criança pode apreender seu erro quando o cilindro não pode ser introduzido.
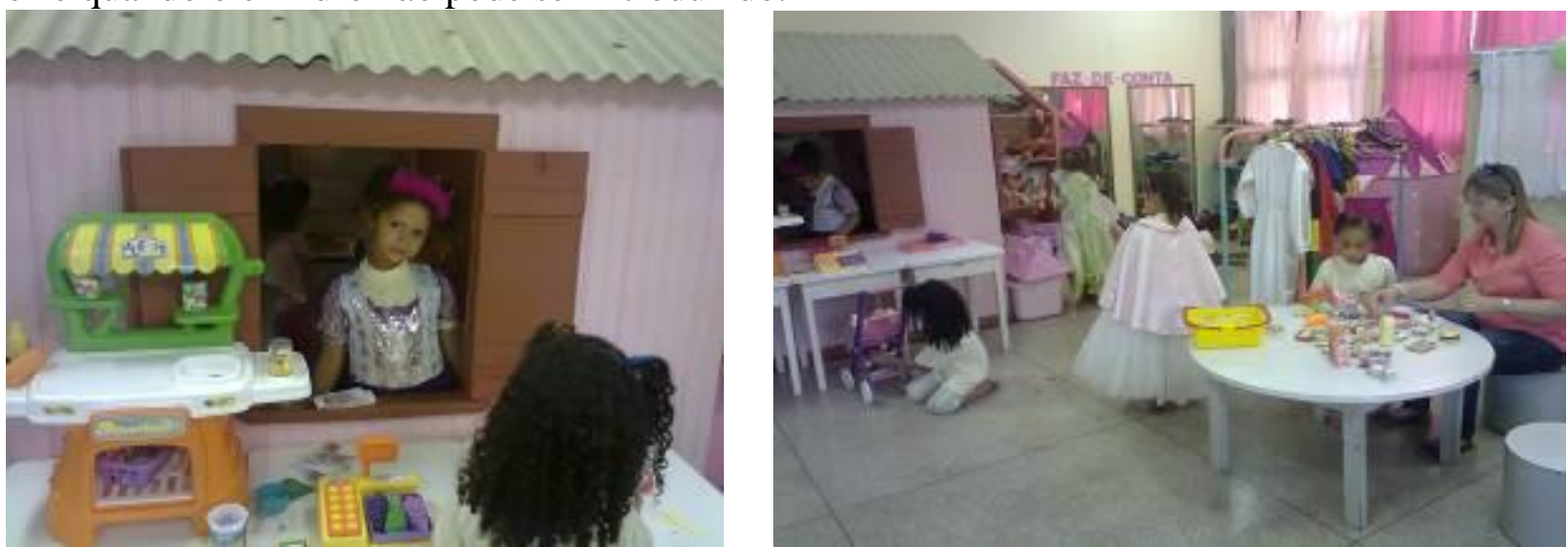

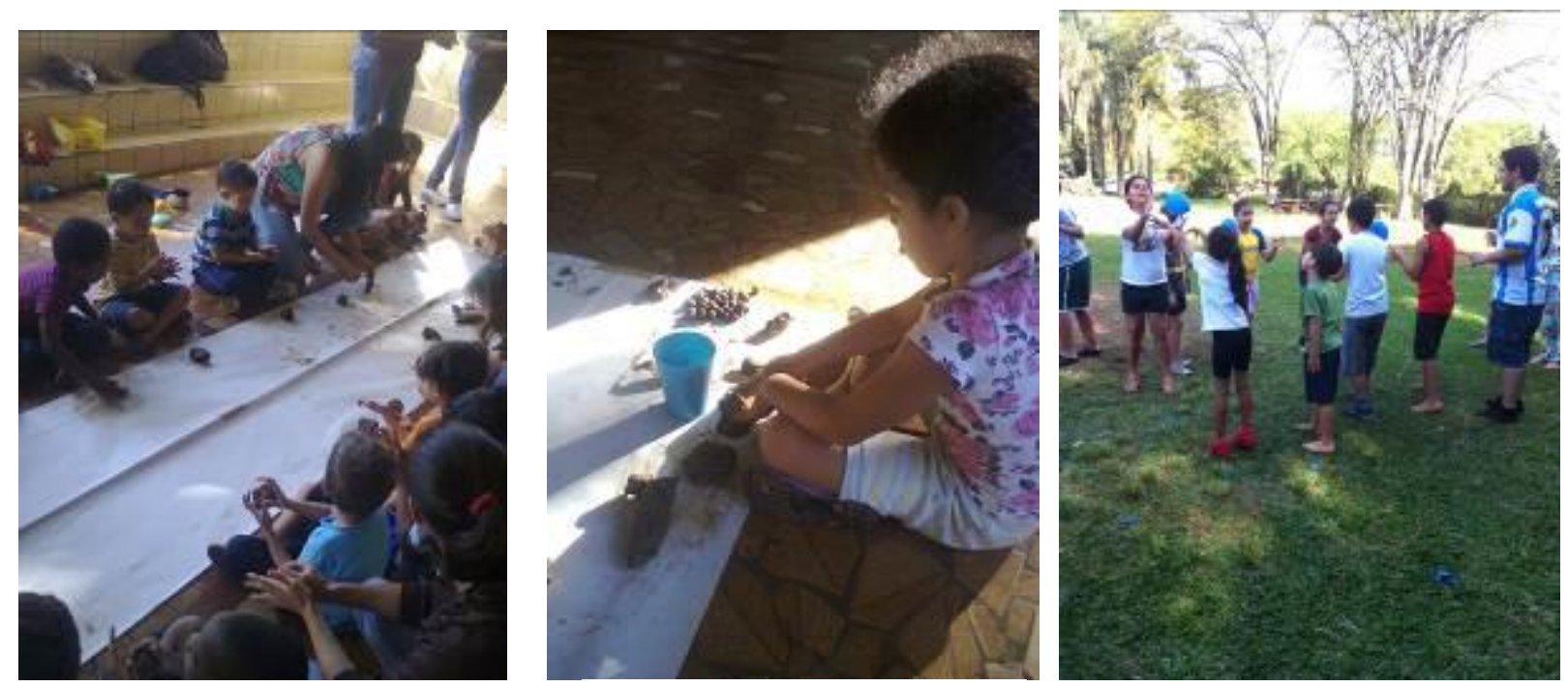

Brincadeiras simbólicas e interativas Fonte: Acervo Pessoal

Na ludoteca para cada um dos sentidos, há um exercício cuja eficácia pode ser ainda aumentada pela eliminação de outras funções sensoriais. Vários elementos são explorados como a argila, a massa de modelar, madeira, bexiga (com agua, farinha, arroz, feijão) etc. Por exemplo, existe um exercício de identificação pelo toque de diferentes tipos de madeira, que é possível tornar ainda mais eficaz vendando os olhos das crianças. Esses exercícios são, conforme pressupostos montessorianos, praticados em grupo e seguidos de uma discussão, o que reforçava seu alcance do ponto de vista dos aspectos sociais da educação das crianças. É assim que as diferentes atividades são destinadas na Ludoteca a conjugar seus efeitos; como Montessori escreveu "para [que a criança] progrida rapidamente, é necessário que a vida prática e a vida social estejam intimamente misturadas à sua cultura" (Montessori, 1972, p. 38)

Assim, Montessori considera a criança um adulto em potencial. A criança num ambiente apropriado, com materiais interessantes que favoreçam o crescimento e a formação de sua personalidade, contribui efetivamente para o desenvolvimento da liberdade, da atividade criativa, da espontaneidade, da individualidade, que dará condições para a autoeducação. Maria Montessori afirma que é necessário que os adultos despertem seus sentimentos de amor e respeito à criança, confiando no seu potencial, e considerando que ela se desenvolva como um todo, pelo processo da autoafirmação. A criança, contudo, precisa de liberdade para escolher a atividade que quer fazer e o tempo em que quer ficar nessa atividade. O mediador, por sua vez, deve incentivá-la com o próprio exemplo, além de, respeitar o ritmo de cada criança e todas as possibilidades de descobertas infantis.

De acordo com Maria Montessori: “abstração não se transmite." É por isso que as crianças precisam conviver as experiências sensoriais, sendo que é necessário que os espaços educativos favoreçam o livre desenvolvimento da criança, implantando as condições educativas necessárias que permitam o desenvolvimento das capacidades humanas elaboradas. Desse modo, as contribuições de Montessori se constituem em campo fecundo para se pensar na educação infantil frente aos desafios impostos pela contemporaneidade.

A autora defende uma concepção de educação que se estende além dos limites do acúmulo de informações, com o projeto de educação para a vida. A filosofia e os métodos elaborados pela médica italiana procuram desenvolver o potencial criativo desde a primeira infância, associando-o à vontade de aprender - conceito que ela considerava inerente a todos os seres humanos. Dessa forma, as atividades de arte são tão importantes, pois nelas a criança pode exercitar o toque de materiais diferentes, desenvolver a percepção e a sensibilidade para cores, 
cheiros, formas e tamanhos de objetos. Montessori (1978) recomenda que as crianças podem se inspirar para desenhar a partir da natureza. Sua crença pessoal foi que a criatividade era um reflexo do mundo natural. A percepção da arte pode ser estimulada, as crianças se espelham nos pais e professores, mas a percepção em si deve partir da própria criança e dessa forma será uma fonte de inesgotável interesse.

Esta abordagem humanista atende as necessidades da criança e expectativas dos adultos ainda hoje. Ela promove à infância num ambiente preparado, o livre desenvolvimento da personalidade, a concentração, a incorporação do conhecimento, a consciência, responsabilidade, decisão e autonomia. Permite que os adultos compreendam os mecanismos que regulam o desenvolvimento da criança e possibilita que as crianças se apropriarem espontaneamente, com alegria e entusiasmo dos elementos fundamentais de nossa cultura, pois o potencial de aprender está em cada um de nós. A educadora acreditava que esses seriam os fundamentos de quaisquer comunidades pacíficas, constituídas de indivíduos independentes e responsáveis. A meta coletiva é vista até hoje por seus adeptos como a finalidade maior da educação montessoriana.

\section{Considerações Finais}

Este artigo teve o propósito de aproximar as contribuições montessorianas sobre a criança e a ludicidiade ao projeto desenvolvido na Universidade Estadual de Londrina, Paraná Ludoteca em Movimento. Estas atividades do projeto proporcionaram oportunidades de observar como estas crianças interagem com a ludicidade no espaço ludoteca para compreender quais as brincadeiras preferidas e se os brinquedos "plastificados" pela tecnologia que enclausuram a criança entre quatro paredes de seu quarto ou da sala de estar, se sobrepõem ao brincar e brincadeiras livres e coletivas. Percebemos que o canto das fantasias foi o local que mais chamou a atenção das crianças e, tanto meninas, quanto meninos mergulharam no universo da fantasia por horas. $\mathrm{O}$ encanto deste espaço foi por conta de proporcionar à criança a possibilidade de ser o que ela quiser e virar super-herói, princesa, palhaço, bailarina, e muitos outros personagens. Nele, a criança, pode escolher o que vestir e como pentear-se, maquiar-se. É uma atividade intensa de significações para a criança.

A Casinha de boneca foi outro espaço muito procurado e também rico em aprendizagens e experiências, pois, nele a criança expressa seus sentimentos suas frustrações, desenvolve sua criatividade, interage com um grupo maior de crianças, reproduzem os papeis sociais que estão acostumadas a vivenciar, questão que estas que são amplamente abordadas por Montessori em suas obras. Nele, a criança reconstrói toda a sua vivencia familiar, os acontecimentos reais ou os desejos. Ela precisa fazer comida e dar de comer, vestir e despir bonecas; organizar a rotina de uma casa, varrendo, passando roupa, lavando, cuidando de "filhos", passeando com eles. É neste espaço que a criança mimetiza-se e transforma-se ora em cozinheiro, comerciante ou naquilo que a imaginação permite: num mesmo espaço cria-se uma lanchonete, supermercado, restaurante, feira, banco ou mesmo para aquilo que foi idealizada, uma casa.

O Canto das Artes buscou resgatar a criatividade das crianças como obstáculo, o avanço das tecnologias que cada vez mais faz com que crianças e adultos se tornem seres práticos, que não reflitam e que não construam novas alternativas de viver e de se expressar. Observamos que neste espaço, as crianças tiveram que ser mais motivadas, pois ofertamos atividades muito semelhantes as que são realizadas na escola. Houve resistência a princípio, mas quando percebiam que a atividade era de livre escolha e com formato mais dinâmico como, manusear tintas e pincéis, massas de modelar, giz de cera, lápis de cor sem tema ou tempo pré determinado, as crianças fizeram com maior prazer. É nisto que nos firmamos, pois as atividades oferecidas no Projeto primam pela liberdade de escolha, de criação e imaginação, onde todos 
podem participar quando e como desejarem; objetivos estes que se aproximam com as contribuições montessorianas.
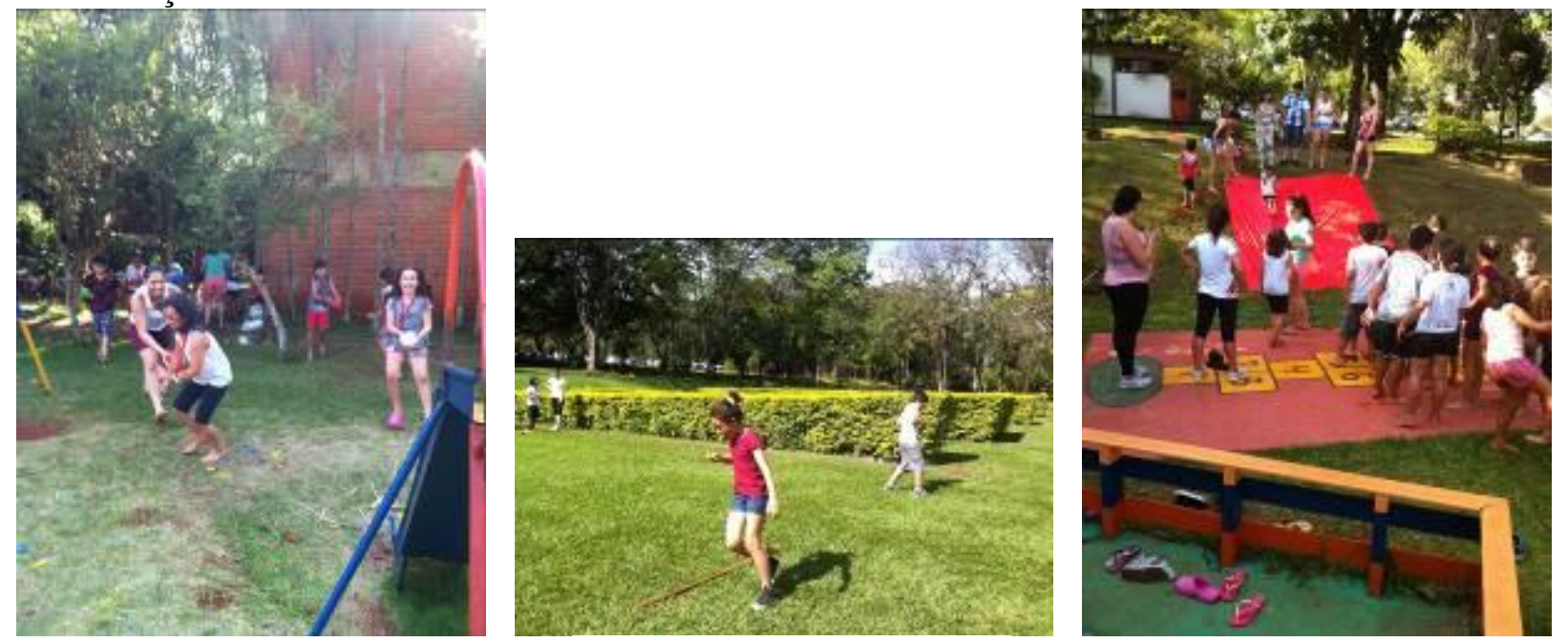

Brincadeiras simbólicas e interativas

Fonte: Acervo Pessoal

$\mathrm{Na}$ área externa, no parque as crianças puderam correr, gritar, superar seus limites, entrar em contato com a natureza e gastar suas energias. É de extrema importância essa vivencia para seu desenvolvimento, e de acordo com Cunha (2010)

A atividade física gera entusiasmo, por essa razão é tão importante. Quando corre, a criança fica alegre; e quando vence obstáculos, desafia os próprios limites e usa a energia para desenvolver a sua coordenação motora, adquirir mais confiança em si própria e aprimorar o seu equilíbrio. (p.25)

O que podemos perceber é que as atividades ao ar livre são um convite a maior interação entre os meninos e meninas. Isto fica comprovado nas atividades que o projeto levou as escolas e para a instituição educativa não formal, como a oficina de confecção de brinquedos e brincadeiras como: pipas, pé de lata, "jogo da velha humano", "vai-vem" em que todas as crianças se interessaram ativamente em participar e "inventar". As atividades que as crianças desenvolveram ao ar livre, tais como jogar bola, amarelinha, perna de pau, pula corda, queimada, observamos que elas as crianças se interessaram mais pelas atividades esportivas. Talvez pelo fato delas sentirem a necessidade de extravasar a energia que ficou aprisionada nas horas que ficaram enclausuradas na sala de aula. Nessas brincadeiras identificamos a necessidade que sentem, do simples gesto de se articular por meio de falas ou expressão corporal, sem contar à interação que conseguimos obter um com o outro. Dessa forma, as atividades desenvolvidas privilegiaram a corporeidade, motricidade e recreação.

Como estas atividades foram realizadas com crianças de diferentes faixas etária (4 a 10 anos), focamos nossa observação em como se dá a relação entre elas. Este foi um dos pontos que consideramos um desafio para os professores, estagiários e as próprias crianças. Desafio para os professores e estagiários, pois as atividades planejadas precisaram ser pensadas levando em consideração características diferentes. Sendo assim, o trabalho pedagógico se apresentou dinâmico onde "o educador é um mediador, um organizador do tempo, do espaço, dos limites, das certezas e até das incertezas do dia-a-dia da criança em seu processo de construção do conhecimento." (SANTOS, 1997, p.61). Na relação entre as crianças este desafio construiu uma relação de cuidado, onde o mais velho sentiu-se responsável pelo mais novo e vice versa. Um exercício em que se aprende o respeito com o outro e as limitações de cada um. Como todas as regras foram construídas coletivamente, as crianças se sentiram a vontade e estabeleceram uma relação mais familiar neste ambiente. As atividades do projeto Ludoteca em movimento passou a 
ser então, uma visita muito esperada nas escolas e na instituição não formal e o espaço lúdico do campus, sua segunda casa, um espaço para extravasar suas emoções e liberar suas energias, onde a única regra é exercitar a imaginação e se divertir!

Podemos, desse modo, inferir que as críticas mais densas ao método Montessori deve-se ao fato de que muitas espaços educativos se intitulam montessorianos sem necessariamente aplicar os métodos de Maria Montessori. É necessário que os profissionais envolvidos na educação e na infância tenham certos de que há a necessidade de formação Montessoriana; haja vista que a falta de conhecimento dos mediadores e professores sobre a importância da autonomia moral e da liberdade infantil com frequência, repercute na conduta destes para com a criança, podendo revelar-se por atitudes coercitivas e autoritárias. Neste momento, pensamos que ter uma compreensão do que seja o legado montessoriano no contexto atual, devolve-nos a compreensão do que seja verdadeiramente a criança e sua infância.

\section{REFERÊNCIAS}

LAMOREA, Maria Lúcia et all. Contribuições do método Montessori. Revista Brasileira de estudos pedagógicos, Brasilia, n. 185, p.90-109, 1996.

MONTESSORI, Maria. Pedagogia Científica. Trad. Aury Brunetti. S.P.: Flamboyant, 1965.

. Mente Absorvente. 2. ed. Portugal, 1985.

. A criança. 3. ed. Rio de Janeiro: Editora Internacional Portugália, s.d.

MONTESSORI, Mario Junior. Educação para o desenvolvimento humano - Para

Entender Montessori. 1. ed. Tradução Leonora Corsino. Rio de Janeiro: Editora:

OBRAPE, s.d.

CAlÓ, G. MONTESSORI, M. IN: CHATEAU (dir.), Os Grandes Pedagogos, Trad. de Maria Emímia Ferros Moura, Lisboa, Livros do Brasil, s/d, [1956], p. 343.

Recebido: maio-15 Aprovado: julho-15 